\title{
Analysis of the organizational culture at a hospital in Benin
}

\author{
Ghislain Emmanuel Sopoh*1, Michael Florian Kouckodila Nzingoula ${ }^{2}$, Charles Jerome Sossa ${ }^{3}$, Yolaine Hessou \\ Ahahanzo-Glele ${ }^{4}$, Edgard-Marius Dona Ouendo ${ }^{2}$, Laurent Tinoaga Ouedraogo ${ }^{4}$, Michel Makoutode ${ }^{1}$ \\ ${ }^{1}$ Department of Health and Environment, Regional Institute of Public Health of Ouidah, University of Abomey-Calavi, Benin \\ ${ }^{2}$ Department of Health Policy and System, Regional Institute of Public Health of Ouidah, University of Abomey-Calavi, Benin \\ ${ }^{3}$ Department of Health Promotion, Regional Institute of Public Health of Ouidah, University of Abomey-Calavi, Benin \\ ${ }^{4}$ Department of Epidemiology and Biostatistics, Regional Institute of Public Health of Ouidah, University of Abomey-Calavi, \\ Benin
}

Received: November 30, 2017

DOI: $10.5430 /$ jha.v7n1p35
Accepted: January 22, 2018

Online Published: January 25, 2018

\begin{abstract}
Objective: To describe the organizational culture (OC) and its strength in a Hospital in Benin.

Methods: This is a descriptive cross-sectional study which involved 121 participants (care providers, support and executive staff) of the Lokossa regional hospital in March 2015. Data on dimensions of OC were collected using a questionnaire developed from the Cameron and Quinn's tools (2006).

Results: The mean age of participants was $41 \pm 8.3$ years and working experience was less or equal to five years in $52.07 \%$. The determined OC was clan-like, hierarchical and results-oriented. This type of OC resulted mainly from cohesion factors, strategic accents, criteria of success, and organizational leadership used by the executive staff. A proportion of 62\% (or 75/121) participants had positive perceptions of this OC. However, participants wished more hierarchical and results-oriented OC.

Conclusions: The study revealed a mixed OC, positively perceived by workers. This reflects their integration within the organization, adherence to the projects and values of the organization and their involvement in work, allowing a constructive work design. Strengthening the hierarchical orientation and result-based option of the OC may improve the performance of the hospital.
\end{abstract}

Key Words: Hospital, Management, Human resources, Organizational culture, Benin

\section{INTRODUCTION}

Organizational culture (OC), defined as "the set of beliefs, values and norms shared in an organization by members whether employees or leaders", influences the welfare of employees, their commitment to productivity and job satisfaction. ${ }^{[1]}$ It is strongly associated with work motivation and influences satisfaction of the staff and the productivity of the organization. ${ }^{[2-4]}$
The experience of hospital management in sub-Saharan Africa shows that the OC is still unknown even though it is the bearer of far-reaching changes in the management culture of a hospital. ${ }^{[5]}$ The management and organization of hospital services seem much more focused on physical, financial and health information systems as a motivator for agents at work, ignoring the ultimate place of human resources and the relationship of these resources among them in job satisfaction and hospital performance. ${ }^{[6]}$ This creates an in-

*Correspondence: Ghislain Emmanuel Sopoh; Email: ghislainsop@yahoo.fr; Address: Department of Health and Environment, Regional Institute of Public Health of Ouidah, University of Abomey-calavi, Benin. 
adequacy between the organizational configuration, which is often deficient, and the relationship between actors and structure for optimal governance. ${ }^{[7]}$

In Benin, despite efforts by the government to improve the management of hospitals, the health system is still plagued by bullying characterized by repetitive strikes, demotivation of care providers and supporters, disaffection for work and a growing degradation of the relationships between users and health workers. ${ }^{[8]}$ This situation is a fortiori testimony to the fact that the management of human resources in hospital services is still an important problem in Benin, and that, taking into account the cultural dimension of the organization could provide some solutions.

This study aims to determine the OC and its strength in a departmental hospital center (CHD) in the south-west of Benin.

\section{MATERIAL AND METHODS}

\subsection{Setting}

The study was conducted at the Mono/Couffo CHD in the town of Lokossa in south-west Benin.

It is an intermediate hospital center in the health pyramid of the country. It serves the departments of Mono and Couffo whose population was estimated at $1,242,571$ in 2013. ${ }^{[9]}$ The hospital has both technical and administrative services. There were 231 technical and administrative staff as at 31 December 2014.

\subsection{Type and study population}

This was a cross-sectional study conducted in March 2015. The study population consisted of health workers, support staff (administrative and maintenance staff) and management staff who were in the CHD at the time of the study.

\subsection{Sampling}

Half of the workforce agents of the CHD was included (i.e. $231 / 2=116$ ) in the study. A $10 \%$ margin of unavailability or refusal was considered. The size of our sample was therefore 128. Participant were selected using simple random technique.

A proportional allocation in all services was used to guarantee the fair share of participants according to services. The weights of each service in relation to the total staff of the center was calculated and related to the sample size to determine the distribution of the sample by service.

\subsection{Study variables}

The models of Cameron and Quinn ${ }^{[10]}$ and Stephen Robbins and Timothy Judge ${ }^{[3]}$ adapted to the context of the study were used to identify the variables of the study and to design the data collection tools.

The model of Cameron and Quinn used an instrument in the form of a questionnaire that requires respondents to answer in six dimensions. This OC assessment instrument had already been usefully used in 2011. ${ }^{[11]}$ Its purpose is to help identify the current $\mathrm{OC}$ of a structure. The same instrument helps to identify the culture that members of the organization want to see in order to meet future environmental demands and opportunities for society. The tool has two columns: a "current" column and another "desired" column. Respondents are asked to fill in the "current" column to give a point of view on their organization; And secondly, the second column to indicate what he would like the organization to look like in the years to come. Beside these columns are a third, that of the dimension to be appreciated. Each dimension has four alternatives and is scored on 100 points overall (alternative A, B, C and D). The 100 points are distributed among these four alternatives according to the perception that the subject investigated to each dimension. Respondents were asked to give more points to the alternative closest to their organization according to their sensitivity and experience. Then follows calculations and a graphical representation the dominant profile of OC in general, that of each of its dimensions and particular characteristics are identified. These dimensions are essential and their positive perception considered as sources of motivation, productivity and customer satisfaction (internal) in the workplace (hospital for our case).

Stephen Robbins and Timothy Judge, determined the strength of the OC based on the positive perception of the OC by employees, through its various components. ${ }^{[3]}$ The strength of the OC reflects the degree of integration of the agent into the structure. The higher this strength $(\mathrm{OC}+)$, the more the individual applies to the job and productivity are guaranteed. The lower it is (OC-), the more the results of his intervention leave something to be desired.

The variable of interest was then OC, characterized by its type (hierarchical, clan, adhocratic, results-oriented) and strength. In accordance with the analysis model used ${ }^{[10]}$ OC was considered as a composite variable, taking into account all perceptions of organizational dimensions as proposed by the model (dominant characteristic, personnel management, cohesion factors, organizational leadership, strategic accents, criteria of success), and the resultant of which determines the type and the strength (see Figure 1).

The independent variables were:

- Personal factors: Gender, age, feeling of belonging to a solidarity and united team, feeling of being valued and respected by the hierarchy, professional value, se- 
niority, professional category and professional status.

- Factors related to working conditions: Average estimated working time per day, level of work environment requirement and availability of work equipment.
- Managerial factors or related to the organization of services: Mode of decision-making, type of service, moral support of the hierarchy, supervision, relationship with management.

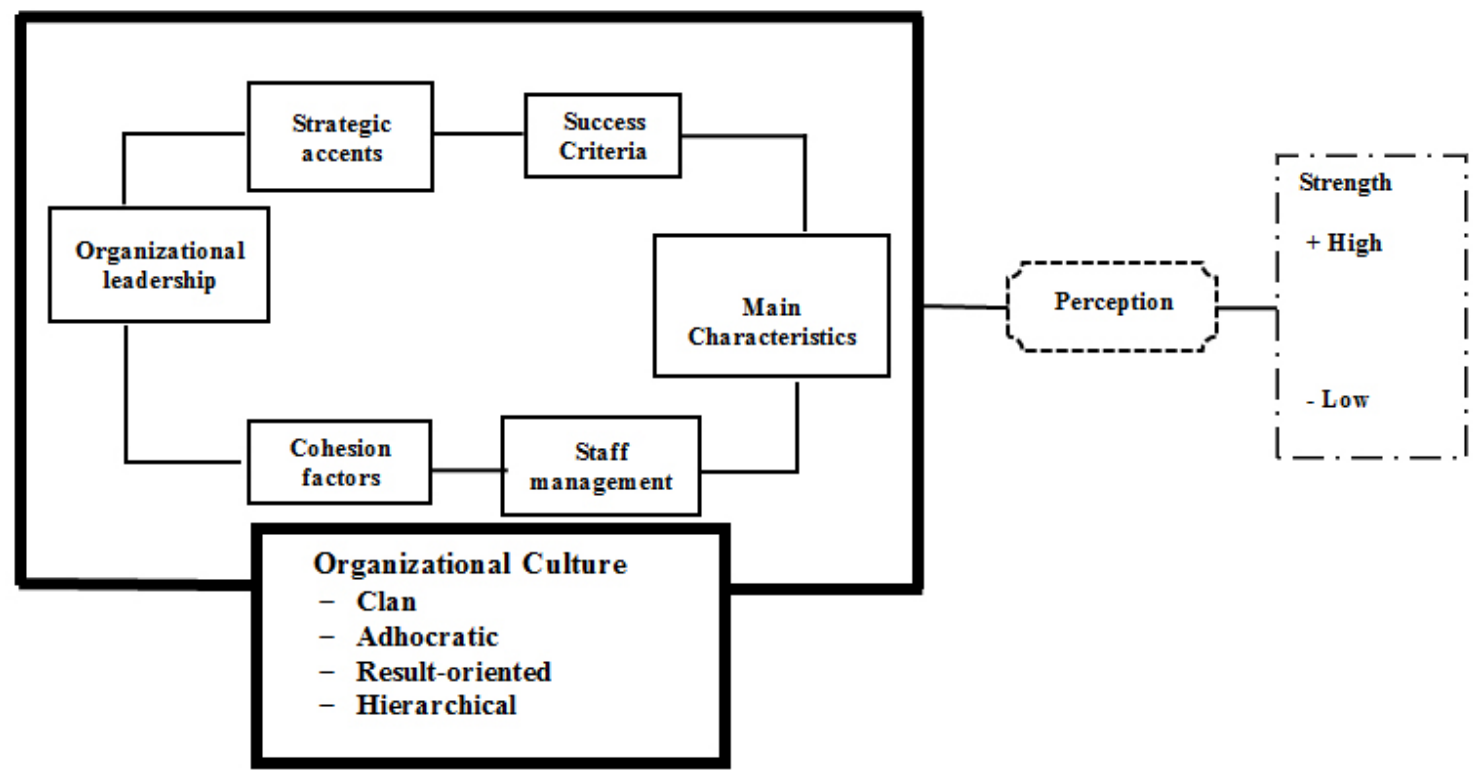

Figure 1. Conceptual frame of OC analysis in CHD Mono/Couffo, Benin, 2015

Adapted from the Cameron and Quinn OC diagnosis model 1998 and the creation of positive OC by Stephen Robbins and Timothy Judge 201

\subsection{Measuring variables}

The measurements allowed to assess each of the dimensions and the overall type of $\mathrm{OC}$ at the time of the study, as well as what the participants would have liked.

\subsubsection{Assessing the dimensions of $O C$}

Six dimensions (the dominant characteristic, organizational leadership, personnel management, cohesion factors, strategic accents and success criteria) were assessed (see Figure 1). Each dimension, assessed as described in subchapter 1.4, included four alternatives in relation to the four types of OC considered A (clan culture), B (adhocratic culture), $\mathrm{C}$ (hierarchical culture) and D (culture of results).

For example, for Dimension 1, if the respondent thought that Variant A was very similar to his organization in comparison to alternatives $\mathrm{B}, \mathrm{C}$ or $\mathrm{D}$, he had to give the maximum point to $\mathrm{A}$ and rest of points distributed between $\mathrm{B}, \mathrm{C}$ and $\mathrm{D}$ always taking into account the reality reflected by the organization for each alternative, making sure that the total is always equal to 100 for each dimension.

\subsubsection{The general appreciation of the type of $O C$}

The means of the individual scores of each alternative (A, $\mathrm{B}, \mathrm{C}$ and $\mathrm{D}$ ) for each dimension were used to derive the overall mean of each type of alternative. The type of OC was

Published by Sciedu Press determined on the basis of a graph in an orthonormal frame as proposed by the Cameroon and Quinn model. ${ }^{[10]}$

\subsubsection{Appreciation of the Strength of $O C$}

Inspired by the work of Cloutier on the relationship between OC and workplace violence ${ }^{[12]}$ and the Cameron and Quinn analysis model, ${ }^{[10]}$ the positive perception of an OC dimension was the result of the positive and negative assessments of the four alternatives relating to this dimension. Operationally, a dimension was considered positively perceived when the sum of the positively appreciated alternatives was $>2$ on an expected total of 4 . It was said to be negative when this number was $<$ or $=2$.

The strength of OC (categorized as high or weak) was the result of the positive and negative perceptions of its dimensions. This strength was said to be high $(\mathrm{OC}+)$ when the sum of the positive perceptions of the six dimensions was $>3$ and low (OC -) when the sum of the positive perceptions of the six dimensions was $<$ or $=3$. Thus, a participant was considered to perceive a positive OC or a high OC strength when the sum of the positive perceptions of the dimensions was greater than or equal to 4 out of 6 . 


\subsection{Data collection procedures}

The questionnaire survey and the literature review were the techniques used in the study. The collection tools were essentially the questionnaire and the counting sheet.

Two (2) higher-level investigators, non-health workers were recruited and trained for data collection. The training focused on the study methodology, the conduct of the hospital survey and the administration of the individual questionnaire.

The data collection phase took place from 13 to 29 March 2015 (17 days). The interviews were conducted individually on appointments.

\subsection{Ethical considerations}

The director of CHD and the departmental Director of health of the Mono and Couffo departments and the participants were informed about the objectives of the study. Oral voluntary consent was obtained from the respondents before the start of data collection. This consent stipulates that participants will not be prejudiced by refusing to participate in the survey or by stopping their collaboration during the study.

\subsection{Data analysis}

The data collected were coded and recorded in Excel ${ }^{\circledR}$. Data analysis was done with Stata ${ }^{\circledR} 11.0$ software and involved both the descriptive and analytical aspects of the study. The proportions were estimated. A graphical representation, in an orthonormal frame of reference, whose dials respectively represent each type of OC, was used to reveal the dominant profile of OC in general, that of each of its dimensions as well as the particular characteristics.

\section{Results}

\subsection{Characteristics of participants}

The characteristics of the participants are described in Table 1.

Of the 128 subjects expected to be surveyed, 121 had participated in the study, representing $94.53 \%$ coverage. The refusal rate was $1.6 \%$ (2/128 subjects approached). Women accounted for $53.72 \%$. The mean age was $41 \pm 8.3$ years with extremes ranging from 24 to 60 years. Of the 121 subjects surveyed, $71.07 \%$ were between 36 and 55 years of age and the majority were contract agents $(n=73$, or $60.33 \%)$.

Most of the participants were medium executive officers $(\mathrm{n}=73,60.33 \%)$ and $52.07 \%(\mathrm{n}=63)$ with less than or equal to 5 years of seniority. The majority of participants $(\mathrm{n}=96,79.34 \%)$ reported that their professional value was based on success in performing their task, while $87.6 \%$ reported having the feeling of belonging to a service, solidarity unit and united $(\mathrm{n}=106,87.6 \%)$ and $75.21 \%$ reported hav- ing the feeling of being respected and valued by the hospital hierarchy.

Table 1. Characteristics of participants, CHD Mono/Couffo, Benin 2015

\begin{tabular}{|c|c|c|}
\hline Designation & Number & $\begin{array}{l}\text { Relative } \\
\text { Frequency }\end{array}$ \\
\hline \multicolumn{3}{|l|}{ Personal Factors } \\
\hline \multicolumn{3}{|l|}{ Sex } \\
\hline - Men & 56 & 46.28 \\
\hline - Women & 65 & 53.72 \\
\hline \multicolumn{3}{|l|}{ Professional status } \\
\hline - Contractual agent of the CHD & 11 & 09.10 \\
\hline - Permanent staff of the government & 37 & 30.58 \\
\hline - Contractual agent of the government & 73 & 60.32 \\
\hline \multicolumn{3}{|l|}{ Professional category } \\
\hline - Subordinate executives & 35 & 28.93 \\
\hline - Senior executives & 13 & 10.74 \\
\hline - Medium executives & 73 & 60.33 \\
\hline \multicolumn{3}{|l|}{ Professional values advocated } \\
\hline - Stimulation & 12 & 09.92 \\
\hline - Success & 96 & 79.34 \\
\hline - Autonomy & 8 & 06.61 \\
\hline - Others & 5 & 04.13 \\
\hline \multicolumn{3}{|c|}{ Sense of belonging to a service / solidarity and unity } \\
\hline - No & 15 & 12.40 \\
\hline - Yes & 106 & 87.60 \\
\hline \multicolumn{3}{|l|}{ Sense of acceptance by colleagues } \\
\hline - No & 8 & 6.61 \\
\hline - Yes & 113 & 93.39 \\
\hline \multicolumn{3}{|l|}{ Sense of respect and valorisation by the hierarchy } \\
\hline - No & 30 & 24.79 \\
\hline - Yes & 91 & 75.21 \\
\hline \multicolumn{3}{|l|}{ Factors related to working conditions } \\
\hline \multicolumn{3}{|l|}{ Average daily working time } \\
\hline - Less than 8 hours & 7 & 05.79 \\
\hline - Equal to 8 hours & 22 & 18.18 \\
\hline - Greater than 8 hours & 92 & 76.03 \\
\hline \multicolumn{3}{|l|}{ Requirement level for the working environment } \\
\hline - Lesser & 90 & 74.38 \\
\hline - High & 31 & 25.62 \\
\hline \multicolumn{3}{|l|}{ Availability of work equipment } \\
\hline - No & 56 & 46.28 \\
\hline - Yes & 65 & 53.72 \\
\hline \multicolumn{3}{|c|}{ Managerial, relational and service organization factors } \\
\hline \multicolumn{3}{|c|}{ Mode of decision-making on activities to be carried out } \\
\hline - Unilateral & 34 & 28.10 \\
\hline - Consensus & 87 & 71.90 \\
\hline \multicolumn{3}{|l|}{ Supervision } \\
\hline - No & 27 & 22.31 \\
\hline - Yes & 94 & 77.69 \\
\hline \multicolumn{3}{|l|}{ Moral support } \\
\hline - No & 32 & 26.45 \\
\hline - Yes & 89 & 73.55 \\
\hline \multicolumn{3}{|l|}{ Type of service } \\
\hline - Administrative department & 33 & 27.27 \\
\hline - Service and care & 74 & 61.16 \\
\hline - Diagnosis help service & 12 & 9.92 \\
\hline - Social service & 2 & 1.65 \\
\hline \multicolumn{3}{|l|}{ Relationship with management } \\
\hline - Not cordial & 32 & 26.45 \\
\hline - Cordial & 81 & 66.94 \\
\hline - Do not pay attention & 8 & 6.61 \\
\hline
\end{tabular}


The average daily working time was $9.8 \pm 0.18$ hours, ranging from 4 to 19 hours. The majority of the subjects surveyed $(n=90,74.38 \%)$ had a favourable opinion of their physical work environment and $53.72 \%$ said they had the required equipment.

More than half ( $\mathrm{n}=94,77.69 \%$ ) reported having supervision of the staff and or their direct hierarchy; And $73.55 \%$ $(n=89)$ reported having moral support from the staff and/or their direct hierarchy in the performance of their duties.

Of the 121 subjects surveyed, $71.9 \%(n=87)$ had reported being involved or their service/unit in the planning of activities by the hierarchy or management staff; More than half ( $n=81,66.94 \%$ ) of the surveyed subjects reported having cordial relations with the management staff.

\subsection{Type of OC}

The OC was of mixed type, predominantly hierarchical and results-oriented in March 2015. The OC desired was clan based (see Figure 2).

\subsection{Description of OC dimensions}

Figure 3 shows the description of current and desired dimensions of OC.

\subsubsection{Current dimensions}

- The dominant characteristic was hierarchical and results-oriented; the same applies to staff management, strategic accents (also adhocratic), and success criteria;

- Organizational leadership was predominantly resultsoriented;

- The factors of cohesion, were predominantly hierarchical, and result oriented.

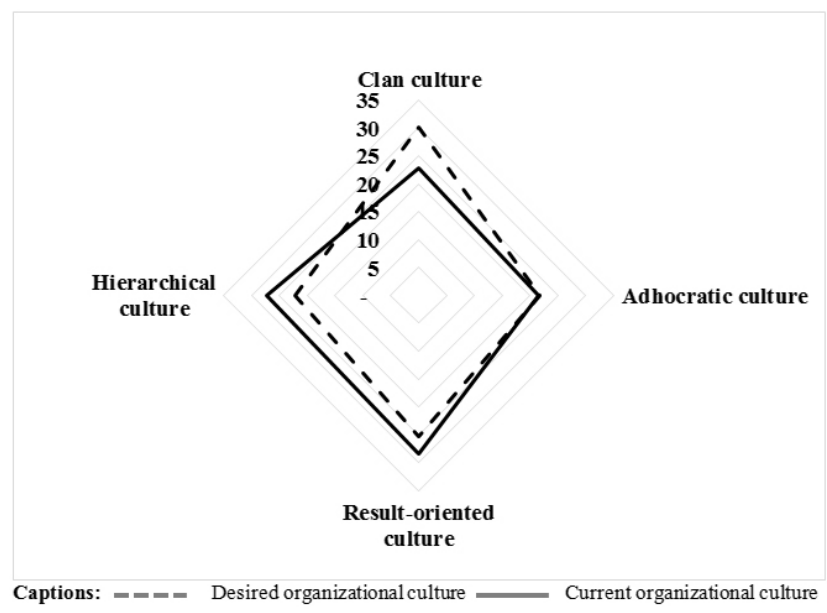

Figure 2. Descriptive schemes of OC (current and desired) at CHD Mono/Couffo, Benin, 2015

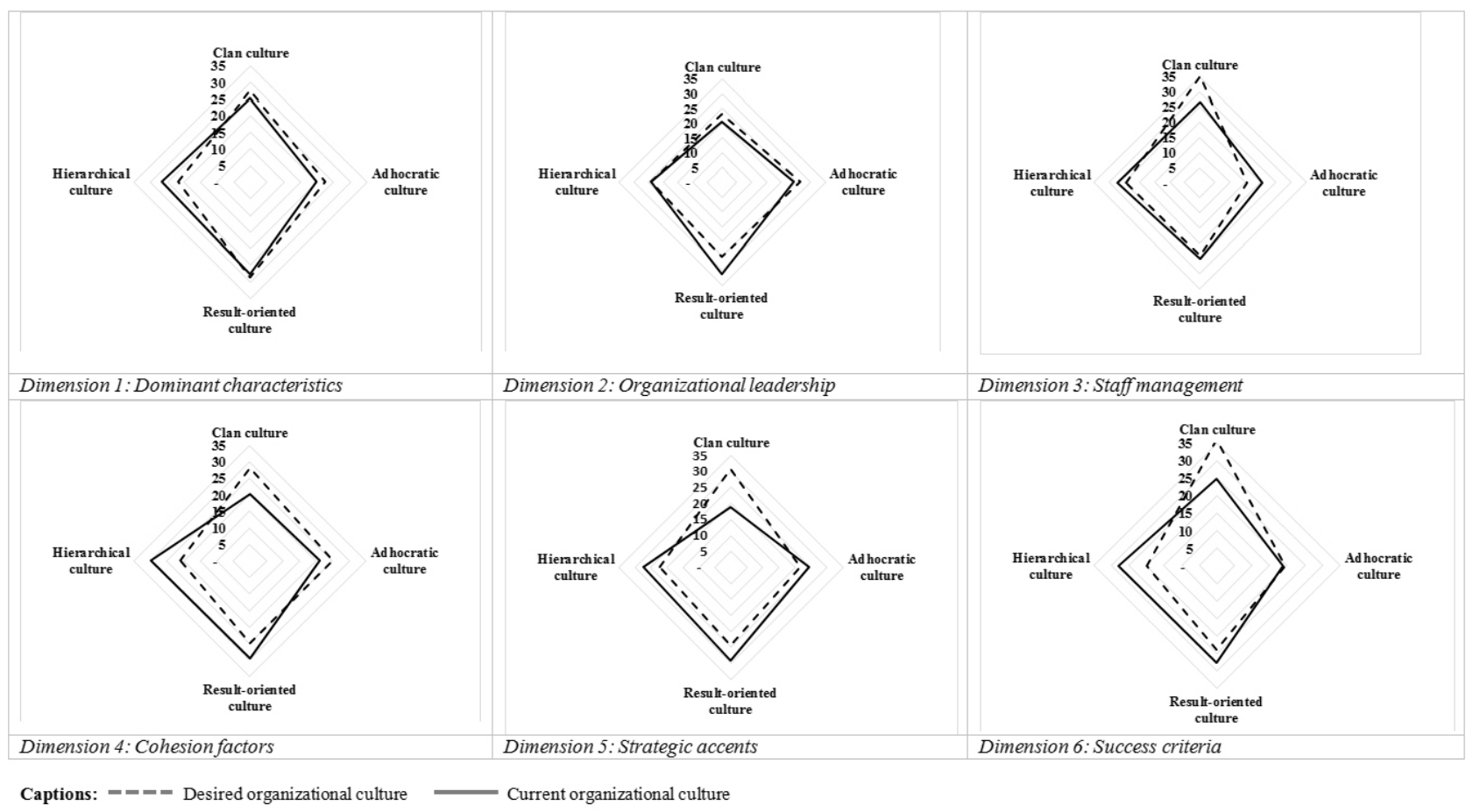

Figure 3. Descriptive schemes of the six dimensions (current and desired) of the OC at CHD Mono/Couffo, Benin, 2015 


\subsubsection{Desired dimensions}

- The desired dominant characteristic was adhocratic and clan based; as well as cohesion factors, strategic accents and success criteria;

- The desired organizational leadership was adhocratic and clan-based;

- The desired staff management was clan and result oriented.

\subsubsection{Strength of $O C$}

The proportion of respondents who perceived a high level of OC (or positive perception of OC) was $62 \%$ (75/121).

\section{Discussion}

This review of OC in hospital is the first of its kind in Benin. From the graphical representations, it enabled us to identify the dominant profile of $\mathrm{OC}$ in general, that of each of its dimensions, particular characteristics and those desired by the staff. This is a descriptive study. The observed differences between the current and desired OC as well as its dimensions have therefore not been statistically tested. Therefore, there may be no statistical difference if quantitative tests were performed. However, such an analysis model, based only on the interpretation of the graphs resulting from the use of the OC assessment tool, has already been used in the past, ${ }^{[11]}$ attesting the reliability of our analysis.

\subsection{The dimensions of $\mathrm{OC}$}

The results showed that the dominant characteristic, staff management, strategic accents and success criteria were hierarchical and result oriented. These dimensions are therefore those which, combined with organizational leadership, sharing the same characteristics, with their strong hierarchical component, have most influenced the general OC. The factors of cohesion, were predominantly result-oriented and hierarchical. However, the desired dimensions are mostly clan-based and adhocratic. According to theories of organizations, ${ }^{[7,13]}$ it must be said that these results show a clever combined application of McGregor's theories X and Y. ${ }^{[13]}$ According to the $\mathrm{X}$ theory of McGregor, most employees are motivated by financial concerns, will avoid working as soon as possible, lack ambition and do not like responsibilities, are not interested in the needs of the company, lack creativity and are reluctant to change. Thus, the manager who follows this theory will tend to apply a hierarchical OC. On the other hand, the $\mathrm{Y}$ theory stipulates that most of the employees are motivated by job satisfaction, are job seekers, demonstrate ambition and seek responsibility, devote themselves to the objectives of the company, are creative and supportive of change. The manager who follows this theory will tend to apply a results-oriented and adhocratic OC. Indeed, in the management of personnel, at the same time that results are expected from the staff, their encouragement, involvement, rapprochement, sense of belonging may be a lever to obtain the best results. This human resource management approach, characterized as clan by placing people at the center of the company's concerns (here the hospital), as expressed by the employees, is in perfect harmony with the theories of the schools of human relations developed among other things by Maslow, Raven and McGregor. ${ }^{[13]}$

Discussions with the management staff of the Mono/Couffo CHD of Lokossa make it clear that several mechanisms were used contributing to this result. The type of culture observed in the organizational leadership dimension denotes the existence of a clear and shared vision of the organization, based on the rigorous application of participatory planning and evaluation procedures embodied in a decision-making recognized by $71.90 \%$ of respondents and regular supervisions which benefited $77.69 \%$ of respondents.

\subsection{The type of $\mathrm{OC}$}

At CHD Mono/Couffo all types of OC were represented. This is in line with the desired ideal in the management of organizations. ${ }^{[7,14]}$ This result is consistent with that of Marchand et al. ${ }^{[15]}$ in their OC study carried out in 2009-2010 on 1,164 workers in 30 Canadian companies (18 manufacturing and 12 service sector). All 4 types of culture were found in their study. However, the predominant culture in their study was of the group type, equivalent to the clan type for our model. The OC predominantly hierarchical in the Mono/Couffo CHD, also combines a results-oriented component (see Figure 2). This type of culture is characterized by a division of tasks, hierarchical control, accountability at the higher levels, meritocracy, impersonal character and attraction of customers, the application of competitiveness and productivity values, but also a personalized approach to individuals, giving them the sense of being valued and belonging to a team, an entity that is theirs. Indeed, $87.60 \%$ of the respondents stated that they felt a sense of belonging to a cohesive and unified service. The majority $(93.39 \%)$ of participants felt accepted by their colleagues and $75.21 \%$ felt they were respected and valued by the hierarchy (see Table $1)$.

The predominant type of hierarchical and result-oriented culture corroborates some theories that public administrations are par excellence the privileged places of hierarchical and results-oriented culture. ${ }^{[7,10]}$ However, in the African context, public administrations are most often subject to a gaudy professional disinvolvement. This result contrasts in many respects with the reality experienced in most public administrations in sub-Saharan Africa and the results of the 
study by Manga Zambo on the analysis of the functioning of the Cameroonian public hospitals which reveals countless problems and their maladjustment to the current competitive environment. ${ }^{[16]}$ The merit of the CHD Mono/Couffo could lie in the know-how and the know-be of the management staff, who can reconcile the procedural rigors of the administration with the participative managerial flexibility and effective leadership based on shared strategic planning, in the management of the center.

\subsection{The strength of $\mathrm{OC}$}

The characteristic "strength of OC" is a recent data of the researchers to highlight the differential effects of the same type of OC on the satisfaction and the productivity between two structures. ${ }^{[7,14]}$ The strength of OC at the Mono/Couffo CHD was predominantly perceived as high (62\%) by the respondents. The strength of culture reflects both the integration of agents within the organization, adherence to the ideals of the organization, and involvement in work. It is what some authors call the constructive conception of labor. ${ }^{[18,19]}$ It is determined by a number of factors, some of which have been highlighted in this study. Some authors measure it by inference based on job satisfaction, ${ }^{[17]}$ others directly by the perception of the dimensions of the OC as in the current study. This result corroborates that of a study conducted by Dufour on organizational behavior and work design among 42 young people with low school capital in the workplace. ${ }^{[18]}$ More than $50 \%$ of these young people had a high perception of OC. Although the measurement methodology used was not the same, the similarity in outcomes may be due to contributing factors, a large part of which would be dependent on the management style and personal aspects.

\section{Conclusions}

This first study of OC in hospitals in Benin highlights the practice of a mixed culture predominantly hierarchical and results-oriented at the Mono/Couffo CHD of Lokossa. This $\mathrm{OC}$ is positively perceived by the majority of the staff, thus attesting to the know-how and know-how of the management staff who combine administration, management and effective leadership in the management of the center. It is suggested that reinforcing this hierarchical result-oriented culture with an improvement of the human relationship, as expressed by the personnel in the desired OC and its various dimensions, may be useful for management of the Hospital.

\section{Conflicts of InTEREST Disclosure}

The authors declare they have no conflicts of interest.

\section{REFERENCES}

[1] Bertrand Y. Organizational culture. Québec: University of Quebec Press and Télé-université, Organizational Communication Collection; 1991. $224 \mathrm{p}$.

[2] Gond JP, Mercier S. Stakeholder theory: a critical synthesis. Conference of the Association of Human Resource Management. AGR. 2004: 379-400.

[3] Robbins S, Judge T. Organizational Behaviors. (16th Edition). Montreuil: Pearson; 2015. 678 p

[4] Ayah R. Scaling up implementation of ART: Organizational culture and early mortality of patients initiated on ART in Nairobi, Kenya. PLoS One. 2018; 13(1): e0190344. PMid: 29293578. https://doi.org/10.1371/journal.pone.0190344

[5] Bernard A, Delvosalle CH, El Hiki L, et al. Implementation of a centralized non-conformity management information system within the Military Hospital in Brussels in "Management and Engineering of Hospital Systems". Lausanne, Switzerland. 2008.

[6] Zongo M, Capochichi J, Gandaho P, et al. Managing the hospital structures of Benin. 2009

[7] Makhloufi I, Saadi J, El Hiki L, et al. Organizational analysis of the hospital through the Mintzberg model: Case of the Cheikh Zaid University Hospital. Public Health. 2012; 24(6): 573-85.

[8] Republic of Benin, Ministry of Health. Strategic Plan for Health Human Resources Development 2009-2018. Cotonou; December 2008. $100 \mathrm{p}$.

[9] National Institute of Statistics and Economic Analysis. RGPH4: What should be done with the population in 2013? Cotonou: Insae; 2015. 33 p.

Published by Sciedu Press
[10] Cameron KS, Quinn RE. Diagnosing and Changing Organizational Culture. New York: John Wiley and Sons; 2006. 242 p.

[11] Suderman J. Using the Organizational Cultural Assessment (OCAI) as a Tool for New Team Development. Journal of Practical Consulting. 2012; 4(1): 52-8.

[12] Cloutier G. A study on the relationship between organizational culture and Workplace Violence. Briefing for Master's in Industrial Relations. Canada: University of Montreal; 2013. 188 p. Available from: http://www.irec.net/upload/File/memoires_ et_theses/186_Cloutier_Genevieve_2013_memoire.pdf

[13] Kennedy C. All theories of management: the essential ideas of the most frequently cited authors. Maxima-Laurent du Mesnil. 2008; 444.

[14] Abbad J. Organization and Hospital Management. Paris: Editions Roger-Levrault; 1997. 417 p.

[15] Marchand A, Haines VY, Dextras-Gauthier J. Quantitative analysis of organizational culture in occupational health research: a theorybased validation in 30 workplaces of the organizational culture profile instrument. BMC Public Health. 2013; 13: 443. PMid: 23642223. https : //doi.org/10.1186/1471-2458-13-443

[16] Pringle J, Weber RJ, Rice K, et al. Examination of how a survey can spur culture changes using a quality improvement approach: a regionwide approach to determining a patient safety culture. American College of Medical Quality. 2011; 26(2): 110-9.

[17] Manga Zambo EJM. Les transformations de la gestion hospitalière dans leurs modernes expressions juridiques et administratives au Cameroun [The transformations of hospital management in their modern legal and administrative expressions in 
Cameroon]. Revue Africaine de Sciences Juridiques [African Journal of Legal Sciences]. 2000; 1(2): 163-1. Available from: http://unpan1.un.org/intradoc/groups/public/d ocuments/cafrad/unpan017583.pdf

[18] Dufour L. Comportement organisationnel et conception du travail des jeunes à faible capital scolaire: proposition d'une typologie [Organizational Behavior and Work Design of Youth with Low School
Capital: Proposed Typology]. IAE d'Aix-en-Provence CEROG. 2012; 26.

[19] Azizollah A, Abolghasem F, Amin DM. The Relationship Between Organizational Culture and Organizational Commitment in Zahedan University of Medical Sciences. Global Journal of Health Science. 2015; 8(7): 195-202. PMid: 26925884. https://doi.org/10.5 539/gjhs.v8n7p195 